\title{
Meeting Campus Linguistic Diversity: A Multilingual Library Orientation Approach
}

\section{Authors}

Jennifer Congyan Zhao, McGill University

Nazi Torabi, McGill University

Sonia Smith, McGill University

\begin{abstract}
This study sought to determine whether offering multilingual orientation sessions to non-native English-speaking students at the beginning of an academic year would improve their knowledge of library services and resources. In September 2015, McGill Library offered 11 orientation sessions in five different languages - English, French, Mandarin Chinese, Persian, and Spanish. A total of 74 students attended the sessions. Noticeable attendance patterns included: (1) sessions offered earlier in the semester had high attendance and (2) the Chinese sessions received the most participants. This study also evaluated students' learning via an assessment questionnaire at the end of each session. The assessment results suggest an increase in students' awareness of services and resources offered by McGill Library. This article reports on the planning, implementation, and assessment of this program; discusses the challenges encountered and lessons learned in organizing and delivering these sessions; and provides recommendations on organizing similar multilingual library orientation programs to address the needs of a diverse student population on campus.
\end{abstract}

Keywords: linguistic diversity, library orientation, non-native English-speaking students, international students, multilingual services

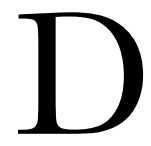
iversity in higher education has become prevalent due to increasing mobility among youth and an ever-globalizing world economy. McGill University, a large research university located in Montreal, Quebec, Canada, enrolled over 39,000 full-time and part-time students from all five continents in 2015 (McGill University, 2015b). McGill's student body represents 158 countries, with international students accounting for over $25 \%$ of the student population. Between 2010 and 2015, the percentage of international students has grown drastically at a rate of 39.9\% (McGill University, 2015c). It is equally important to note that more than half of the entire student population has a native language other than English (McGill University, 2015a): 47\% Anglophone (English speaking), 20\% Francophone (French speaking), and the remaining 33\% allophone (McGill University, 2015a). The term allophone, particularly 
in Quebec, means having a first language other than French, English, or an aboriginal language (Barber, 2005).

In fall 2015, four liaison librarians at McGill University (from the Schulich Library of Science \& Engineering, the Humanities \& Social Sciences Library, and the Nahum Gelber Law Library) offered library orientation sessions in multiple languages - English, French, Mandarin Chinese, Persian, and Spanish - at the beginning of the academic year. The main goals of this initiative were to proactively meet the library and information needs of the linguistically diverse student population and to determine whether multilingual orientation sessions would improve non-native English-speaking students' knowledge of the library's services and resources.

The librarians adopted the library's four promotional themes - Access, Collection, Space, and People - to design the multilingual library orientation sessions (McGill University Library, 2016; see Figure 1) in the hope of providing a full spectrum of its services and resources to students, especially those whose mother tongues were not English. It was assumed that non-native Englishspeaking students (including international students) might not be aware of the depth of services available through the McGill Library, since library services may vary from one country to another.

This paper describes the multilingual library orientation program's session content, promotional strategies, evaluation results, as well as challenges encountered in organizing and delivering this initiative. It also provides lessons learned on the design and delivery of the multilingual library orientation sessions.

International Journal on Information, Diversity and Inclusion, Vol. 1, 2016 publish.lib.umd.edu/IJIDI/ 

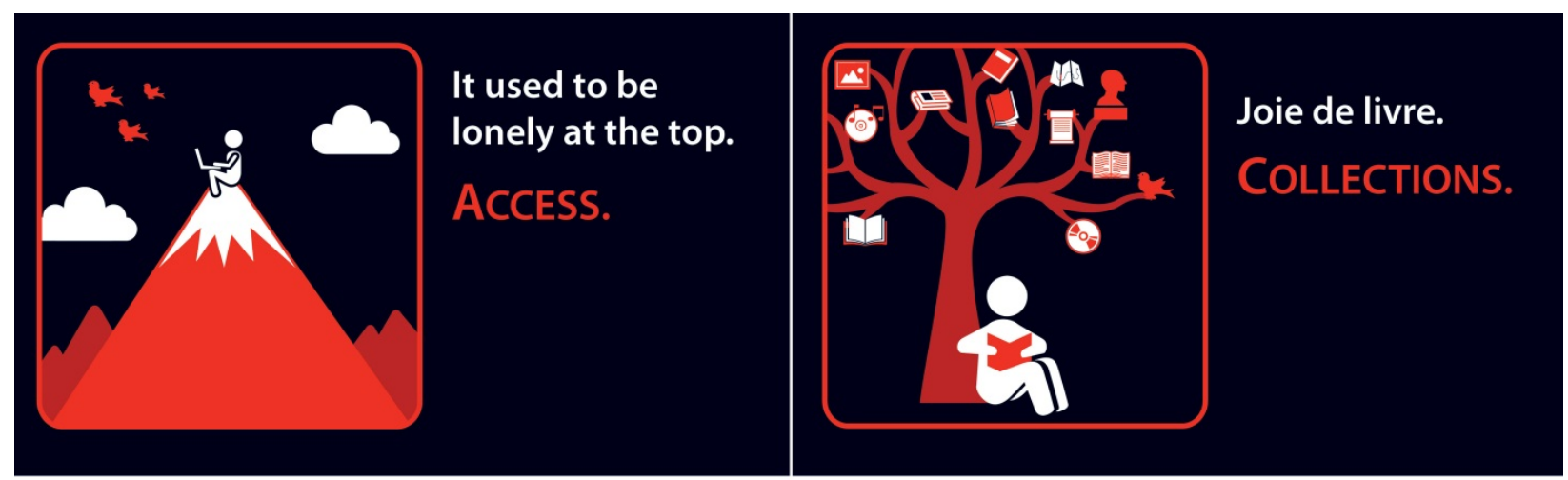

mcgill.ca/library/orientation

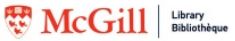

mcgill.ca/library/orientation

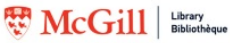
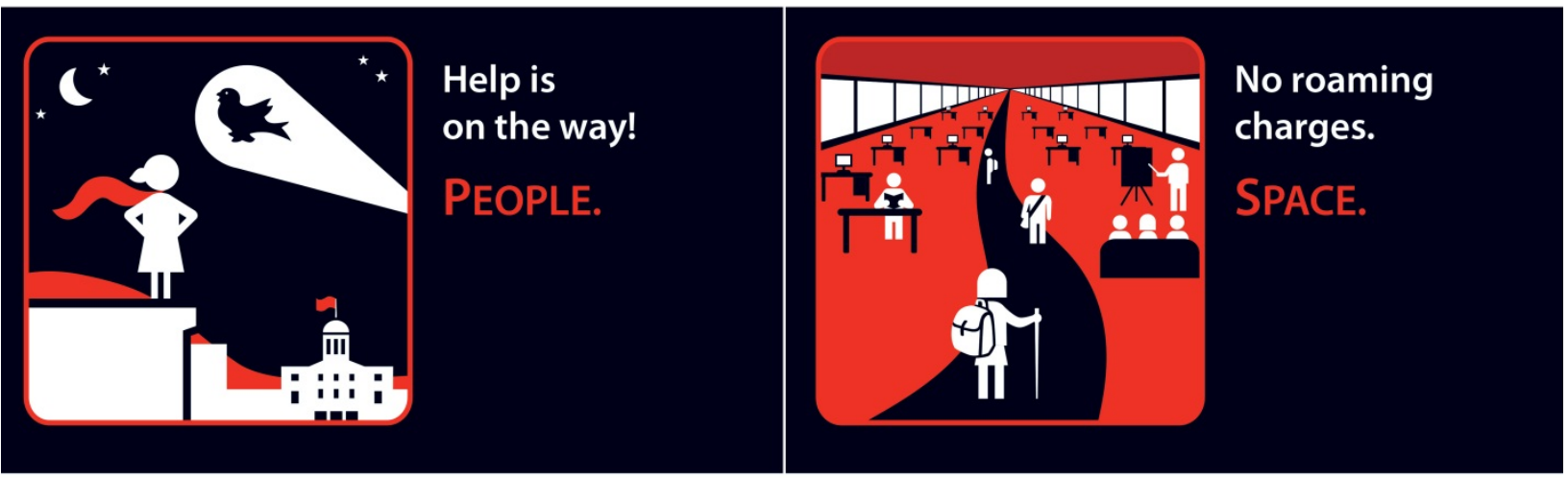

mcgill.ca/library/orientation

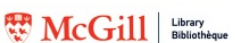

mcgill.ca/library/orientation

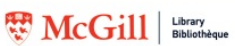

Figure 1. The promotional themes of library orientation at McGill University

\section{Literature Review}

\section{Non-Native English-Speaking Students and Their Challenges}

There are numerous studies reporting on challenges that non-native English-speaking students face in North American universities when they seek and use information. English proficiency, previous library experience, and cultural differences are the main factors that affect their use of the library and information (Hughes, 2010; Ishimura \& Bartlett, 2014; Morrissey \& Given, 2006; Nzivo \& Chuanfu, 2013; Sin, 2015; Zhao \& Mawhinney, 2015).

Howze and Moore (2003) conducted a study about international students' understanding of concepts related to the use of library-based technology and reported that "language is enough of a barrier to the non-native speaker without the additional layers of jargon and the vocabulary of technology" (p. 64). Terms such as catalogs, stacks, citations, and databases are not common knowledge among these students. A study looking at international students' preferences in using libraries and library resources reported that a majority of students have difficulty understanding database search terms in English and most international students are interested in obtaining library information in their native languages or prefer to use library databases in their own

International Journal on Information, Diversity and Inclusion, Vol. 1, 2016 publish.lib.umd.edu/IJIDI/ 
languages (Zhuo, Emanuel, \& Jiao, 2007). In a survey conducted at 165 university libraries, the dominant challenges international students face as they enter academia tend to be associated with the library/education system (Baron \& Strout-Dapaz, 2001). A study investigating international business students' previous experiences with electronic resources and libraries reported that most students have no prior library experience. Furthermore, there is no correlation between the length of stay in the United States and their preferred use of electronic resources. Therefore, the author recommended that library instruction and outreach programs be incorporated into a departmental orientation session to benefit international students at early stages of their studies (Song, 2004).

\section{Academic Library Initiatives: Making Connections with Non-Native English- Speaking Students}

In the literature, there are many recommendations on how to improve library instruction practices for international students. It is important to tailor library instruction services for this population in order to compensate for students' language difficulties and to increase their awareness of library services (Hughes, 2010; Ishimura \& Bartlett, 2014). Working directly with international students to better understand their information-seeking behaviors and information needs is essential. One study investigated the intervening factors that affected the information use and needs of international students from Japan and stated that providing detailed assignment guidelines helped Japanese students feel less anxious and more confident about their research process. The same study also explored how Japanese students seek help and interact with peers (both Canadian students and other Japanese students), professors, and librarians. Understanding of academic expectations in Canada was another factor that influenced their information behavior (Ishimura \& Bartlett, 2013). Zhao and Mawhinney (2015) examined the information literacy challenges of entry-level engineering students, noticing that the lack of knowledge of basic library resources and services and the evaluation of sources is challenging for native Chinese-speaking students. They suggested offering "targeted initiatives" to this specific group through library orientations and workshops. Downing and Klein (2001) created a web-based multilingual library tour to increase awareness of library services for this large and growing student population. Greenberg and Bar-Ilan (2014) conducted a study in a multicultural university to understand information needs and information-seeking behavior of three groups of students with different native languages (Hebrew, Arabic, and Russian). They reported that the main differences among these groups of students were their use of search engines and reference services and the number of resources used to complete an assignment. One of their main recommendations was to offer special services to different native language student groups in their own native languages. Bosch and Molteni (2011) created Spanish library instruction sessions that their students appreciated. The aims of these sessions were to create a culture of inclusiveness and foster positive feelings toward the library as a place for learning. They concluded that library instruction in students' native languages has many benefits for international students, as "it enhances student-library connections, promotes a better understanding of library services in the American institutions, augments information literacy skills, and reduces library anxiety" (p. 146).

While providing information literacy sessions to international students in their own native language might not always be feasible, it is important for librarians to be resourceful and creative in offering learning opportunities to students in their native languages whenever possible. This

International Journal on Information, Diversity and Inclusion, Vol. 1, 2016

publish.lib.umd.edu/IJIDI/ 
article introduces a new practice in the field by describing a program in which the librarians taught library orientation sessions in multiple languages at the beginning of an academic year.

\section{The Approach}

To familiarize students with the library's services and resources in a way that mirrors student linguistic diversity, the McGill Library offered library orientation sessions in September 2015 in five different languages - English, French, Mandarin Chinese, Persian, and Spanish. These languages are among the top ranked mother tongues of McGill students. After the idea of offering multilingual library orientations to non-native English-speaking and international students was shared among interested librarians, a team of four liaison librarians quickly formed, each of whom was a native speaker of French, Mandarin Chinese, Persian, or Spanish. This section details the preparation, implementation, and assessment plans of this multilingual library orientation program.

\section{Naming the Program}

The first task was to create an official title for the initiative that reflected the program goals. After a brainstorming meeting, several names were considered, for example, "Library Orientation in Your Language," "Library Orientation for International Students," and "Multilingual Library Orientation." Finally, "Multilingual Library Orientation" was selected, as it was most inclusive, accounting for native speakers regardless of their place of origin (McGill University has a large number of native French-speaking students from Quebec, Canada, and other French-speaking countries).

\section{Teamwork and Preparation}

Organizers of this initiative were a team of librarians enthusiastic about increasing library use among students, especially those whose native languages were not English. In addition to delivering orientation sessions in a non-English language, these librarians divided the preparation work among themselves, including designing instruction content; promoting the program; creating publicity materials; organizing session logistics such as venue, registration, and supplies; and developing assessment strategies. This team approach proved effective, as it allowed for the preparation to be completed within three weeks.

\section{Program Promotion}

A total of 11 sessions, 2 in English, 2 in French, 3 in Mandarin Chinese, 2 in Persian, and 2 in Spanish, were planned for September 2015, with 2 to 3 sessions in each week. In the middle of August, the program description was posted on the library's website and session registration forms opened. Meanwhile, a promotional campaign for the program started with tailored announcements targeting different student audiences. Two communication channels were used in the promotion of the multilingual orientation sessions:

1. Communication targeting all students:

- McGill Library's homepage and social media,

International Journal on Information, Diversity and Inclusion, Vol. 1, 2016 publish.lib.umd.edu/IJIDI/ 
- faculty and departmental listservs and orientation sessions,

- McGill student society newsletters,

- printed posters (see Figure 2) in library branches and strategic campus locations,

- smaller pamphlets handed out to students at library service desks and departmental orientation events, and

- public display screens inside library branches and elsewhere on campus.

2. Communication targeting non-native English-speaking students:

- International Student Services' social media,

- Engineering Student Centre's newsletter (this group was targeted because of McGill's latest enrollment statistics: the Faculty of Engineering enrolled 1,669 international students, accounting for 36\% of all engineering students; K. Massey, personal communication, December 9, 2015), and

- international student groups at McGill University. 


\section{Multilingual Library Orientation Sessions}

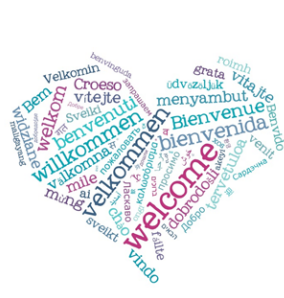

This September, the McGill Library will be offering library orientation sessions in multiple languages - English, French, Mandarin Chinese, Persian and Spanish. Whether or not you use English as a second

language, you are welcome to attend a session and become an efficien

user of the library's services. In the one-hour session, you will learn to:

- Findinformation on the Librarywebsite

- Find books in the Library Catalogue

- Locate textbooks on course reserve

- Access e-resources while off campus

- Seek help from a librarian

If interested, please sign up for a session at

http://bit.ly/MultilingualOriontation. Should you have any questions,

please email jennifer.zhao@mcgill.ca.

Thursday, September 3, 2015 at 11:45 am

Multilingual Library Orientation Sessions - in Mandarin Chinese (由普通话讲解)

(This session is the same as Schulich MyLibrary Workshop)

Schulich Library of Science and Engineering, Room 313, Macdonald-Stewart Library Building

Wednesday, September 9, 2015 at 13:00 pm

Multilingual Library Orientation Sessions - in Spanish (en Español)

Humanities and Social Sciences Library, Cyberthèque, Redpath Library Building

Friday, September 11, 2015 at 11:30 am

Multilingual Library Orientation Sessions - in Mandarin Chinese (由普通话讲解)

Humanities and Social Sciences Library, Cyberthèque, Redpath Library Building

Friday, September 11, 2015 at 13:00 pm

Multilingual Library Orientation Sessions - in Spanish (en Español)

Humanities and Social Sciences Library, Cyberthèque, Redpath Library Building

Monday, September 14, 2015 at 10:45 am

Multilingual Library Orientation Sessions - in Persian (جكَونه از كثابخاته خود حداكثر استقاده را بيريج)

(This session is the same as Schulich Mylibrary Workshop)

Schulich Library of Science and Engineering, Room 313, Macdonald-Stewart Library Building

Tuesday, September 15, 2015 at 14:30 pm

Multilingual Library Orientation Sessions - in Mandarin Chinese (由普通话讲解)

Humanities and Social Sciences Library, Cyberthèque, Redpath Library Building

Friday, September 18, 2015 at 10:00 am

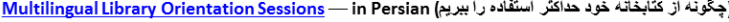

Humanities and Social Sciences Library, Cyberthèque, Redpath Library Buildin

Friday, September 18, 2015 at 11:30 am

Multilingual Library Orientation Sessions - in English

Humanities and Social Sciences Library, Cyberthèque, Redpath Library Building

Tuesday, September 22, 2015 at 10:00 am

Multilingual Library Orientation Sessions - in French (en français)

Humanities and Social Sciences Library, Cyberthèque, Redpath Library Building

Friday, September 25, 2015 at 10:00 am

Multilingual Library Orientation Sessions - in French (en français)

Humanities and Social Sciences Library, Cyberthèque, Redpath Library Building

Figure 2. Printed promotional poster

\section{Orientation Sessions}

The four librarians on this team gave the orientation sessions using consistent learning objectives:

1. navigate and find library services using the library's website,

2. locate different library branches and learn how to use the library as a space,

3. become familiar with the digital and physical collections,

4. access e-resources off-campus, and

5. find and contact subject specialist librarians at the McGill Library.

Additionally, all the language sessions used consistent teaching activities. To better engage students, at the beginning of each session they were asked to write down three to five questions

International Journal on Information, Diversity and Inclusion, Vol. 1, 2016

publish.lib.umd.edu/IJIDI/ 
about McGill Library and post the questions on the corresponding white boards labeled Access, Collections, People, and Space in the classroom. The librarian then guided the students in finding answers to these questions by explaining how different library services and resources work. The questions not answered during the librarian's presentation were addressed in a question period following the presentation.

While many of these orientation sessions were offered in various non-English languages, the librarians purposely taught students equivalent English terminology wherever appropriate, with the hope of helping students build their knowledge of library-related vocabulary in English.

\section{Assessment}

At the end of each session, participants were asked to complete an assessment questionnaire that included seven questions. In addition to seeking information regarding students' attitudes toward the value of the multilingual orientation sessions, these questions aimed to measure students' learning from these sessions. These questions were as follows:

1. A data librarian can help you find statistical, socioeconomic, geospatial, and other types of data for your research. Please find a data librarian's email using McGill Library's website and write it below.

2. Please use WorldCat to find a book about English writing, especially for non-native English speakers, and write down the title, author(s), publication year, and publisher below.

3. Please write down opening hours and service hours on Saturday, October 31, in the Humanities and Social Sciences Library. You may find the information on the library website.

4. Was there anything you would have liked to see covered in more depth? If yes, please write it below.

5. What was the most useful thing you learned from today's session?

6. Any further comments? Please write them below.

7. If you come from outside of Quebec, please specify the country and the province or state where you are from, as well as your mother tongue.

\section{Results}

\section{Attendance}

After each orientation session, the number of attendees was recorded. At the end of the program, all the students' responses to the end-of-session assessment questionnaire were analyzed. Among the 117 students registered, 74 (63\%) attended. The Mandarin Chinese sessions received the highest attendance, with 51 participants $(69 \%)$. The other language sessions received relatively low attendance, accounting for 23 of the 74 participants (31\%). Figure 3 displays the percentage of student attendance in these sessions by language.

International Journal on Information, Diversity and Inclusion, Vol. 1, 2016 publish.lib.umd.edu/IJIDI/ 


\section{Student Attendance by Language (Percentage)}

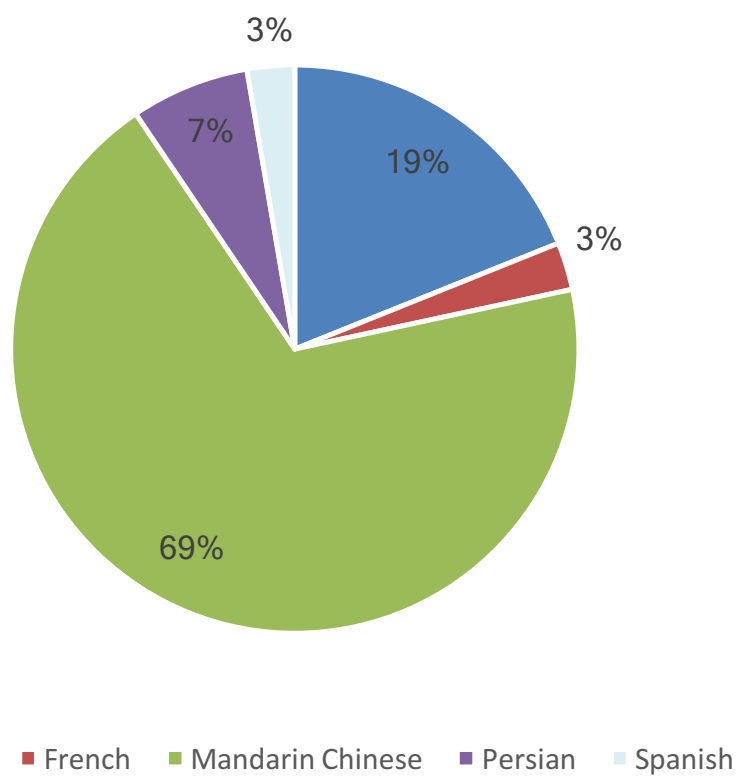

Figure 3. Student attendance by language (percentage)

The three Chinese sessions were offered in the first, second, and third weeks in September and received 29, 15, and 7 attendees, respectively. In comparison, French sessions were offered at the end of September and had low attendance. English, Persian, and Spanish sessions that were offered in the second and third weeks of September had relatively low attendance.

\section{Assessment}

The Multilingual Library Orientation assessment questionnaire received 32 responses (43\% response rate), of which 28 were from the Chinese orientation sessions.

In response to Question 1, while many students filled out the correct data librarian's contact information, a noticeable number of students provided the email address of their liaison librarian instead. Answers to Question 2 and Question 3 were fairly satisfactory, with correct response rates of $91 \%$ and $81 \%$. In Question 4, when students were asked if there was anything they would have liked covered in greater depth during the session, students suggested having more instruction on library research methods, including advanced database searching, content related to completing an academic research assignment, locating current articles, and locating subjectspecific materials. Other recommended topics included learning how to access French learning materials and how to borrow textbooks. Question 5 asked for the most useful content they learned during the session. Many respondents found it was helpful to know how to search for books, especially textbooks, as well as how to access them in either print or electronic format. Other topics that respondents found useful included learning how to request books, finding past exams, seeking help from a librarian, booking a group study room, locating information on the library website, and using printing and scanning equipment. Question 6 was an open-ended

International Journal on Information, Diversity and Inclusion, Vol. 1, 2016 publish.lib.umd.edu/IJIDI/ 
question soliciting additional comments. Most students regarded the orientation instructions as useful and provided positive comments, such as "This library orientation is great and it let me be familiar with nearly everything about library services;" "This event is great;" and "This course has been very useful for me!" There were also suggestions for giving more workshops in languages other than English, particularly in Mandarin Chinese. The number of responses to Question 7, asking about the participants' mother tongue, was very low. The majority of answers indicated various provinces in China and Chinese language as their first language.

\section{Discussion}

Since the study assessment observed the increase in students' library knowledge after the multilingual orientation session and their positive perception toward the session, the authors concluded that this initiative achieved its overall goals - to proactively meet the library and information needs of McGill's linguistically diverse student population and to determine whether multilingual orientation sessions would improve non-native English-speaking students' knowledge of library services and resources. However, it was interesting to see that the attendance numbers dropped as the semester progressed. It was speculated that students may be more willing to attend extracurricular activities, such as the library orientation session, at the very beginning of the term while their schedules are more flexible and they are less busy with their schoolwork.

The initiative did not receive consistently high attendance in all sessions offered in all languages. The high attendance of native Chinese-speaking students in this program might be attributed to the size of the Chinese student population at McGill, the third largest behind English-speaking and French-speaking students. The high attendance may also suggest that native Chinesespeaking students in particular appreciate having a library orientation that is offered in their native language at the start of their studies.

While McGill University has a large number of Francophone students, Francophone attendance was remarkably low. This may be due to the librarian for French Language and Literature being already well embedded in two required undergraduate and graduate French literature courses, as well as in an advanced French language course for French learners. However, this does not explain the absence of Francophone students from faculties and departments outside of the Department of French Language and Literature and the French Language Centre. One speculation is that the Francophone students might be relatively comfortable speaking and studying in English and familiar with library services and resources in North America. As a result, they choose not to attend a session offered in French. This is an interesting observation, and future studies in this area might improve the understanding of library and information needs of Francophone students.

The low attendance in the English sessions may be a result of other library orientation activities being offered in English at the same time. The librarian who led the English sessions also noticed that the student attendance was a mixture of allophones and Anglophones. However, the authors could not specify the ratio due to the lack of responses to the assessment questionnaire. It is possible that Francophiles and Hispanophiles may have attend the French and Spanish sessions as a way to practice and improve their language skills, but may have neither French nor Spanish as their native languages. This logic may also be true for English language and other language

International Journal on Information, Diversity and Inclusion, Vol. 1, 2016 publish.lib.umd.edu/IJIDI/ 
sessions. Thus, one cannot assume that all participants of a particular language session are native speakers of the language used in that session.

While the findings are limited to a small sample of the student population, the positive feedback from session participants confirmed the value of this multilingual initiative. The assessment results from the questionnaire provided some insights about what students learned from the sessions and how the teaching can be improved in the future. The majority of students were not able to locate the contact information for the data librarian, most likely because there was too much emphasis on the liaison librarian's services during the session. As a result, students might have built an impression that they could seek any help from their liaison librarian, including finding data or connecting with the data librarian, and they might not be aware that there would be a separate librarian offering data services. Therefore, it remains essential to continue promoting liaison librarians' roles, since it is not feasible to familiarize all students with the diverse librarian roles on campus. The student comments also suggest that students are interested in learning advanced searching skills for their subject area in addition to the basic content covered in the orientation sessions.

\section{Recommendations}

While delivering the multilingual orientation session, the authors recognized that incorporating alternative formats of materials such as an integrated library tour would be beneficial to students and their acclimatization to the library. During the tours, the librarian could provide instructions on how to log into the printer, locate the book return bin, use the selfcheckout machine and course reserves, as well as explore various study areas. In addition, McGill Library has created a series of video tutorials related to various library resources and services available on the library's website. These self-directed online materials are useful to augment the in-person sessions, especially for international students when they need to learn about the library at their own pace. In the future, incorporating online content into the orientations sessions may be beneficial.

Due to the lack of multilingual library staff, it is not always feasible for every library to offer inperson multilingual library orientation. However, librarians can be resourceful and creative by collaborating with multilingual students to offer a similar program. It is very common to see more and more international students in North American university campuses. They are library clients, but they may also be trained to supplement existing library services, such as by contributing to the library's multilingual orientation events and online orientation materials.

In the future, it would also be interesting to explore whether students from diverse language groups share similar library needs and if library-related questions vary among students with different native languages or nationalities. All in all, it is essential to become acquainted with the needs of a university's diverse student population in order to better address the library and information needs of this growing community.

\section{Conclusions}

The Multilingual Library Orientation is effective in meeting linguistic diversity on campus, especially for students whose culture, language, and previous library experience differ largely

International Journal on Information, Diversity and Inclusion, Vol. 1, 2016

publish.lib.umd.edu/IJIDI/ 
from North American students. However, planning a successful multilingual orientation program requires librarians who are comfortable communicating and teaching in different languages. Sessions must be offered at an appropriate time that meets students' scheduling needs. Multiple channels and collaborative promotions are essential in order to market the program to a wide audience. The high attendance in the Chinese sessions suggests that library orientation is in particular welcomed by Chinese-speaking students.

\section{Acknowledgement}

The authors are grateful to Ms. Tara Mawhinney for her constructive feedback on this paper.

\section{References}

Barber, K. (2005). The Canadian Oxford dictionary (2nd ed.). Oxford, UK: Oxford University Press. Baron, S., \& Strout-Dapaz, A. (2001). Communicating with and empowering international students with a library skills set. Reference Services Review, 29(4), 314-326.

Bosch, E. K., \& Molteni, V. E. (2011). Connecting to international students in their languages: Innovative bilingual library instruction in academic libraries. In P. Jackson \& P. Sullivan (Eds.), International students and academic libraries: Initiative for success (pp. 135-150). Chicago, IL: Association of College and Research Libraries.

Downing, A., \& Klein, L. R. (2001). A multilingual virtual tour for international students: The web-based library at Baruch College opens doors. College \& Research Libraries News, 62(5), 500-502.

Greenberg, R., \& Bar-Ilan, J. (2014). Information needs of students in Israel - A case study of a multicultural society. The Fournal of Academic Librarianship, 40(2), 185-191.

Howze, P. C., \& Moore, D. M. (2003). Measuring international students' understanding of concepts related to the use of library-based technology. Research Strategies, 19(1), 57-74.

Hughes, H. (2010). International students' experiences of university libraries and librarians. Australian Academic and Research Libraries, 41(2), 77-89.

Ishimura, Y., \& Bartlett, J. C. (2013). Uncovering the research process of international students in North America: Are they different from domestic students? Information Research - An International Electronic Fournal, 18(1), paper 564. Retrieved from http://www.informationr.net/ir/18-1/paper564.html\#.WFK5W1MrKM8

Ishimura, Y., \& Bartlett, J. C. (2014). Are librarians equipped to teach international students? A survey of current practices and recommendations for training. The Fournal of Academic Librarianship, 40(3-4), 313-321. http://dx.doi.org/10.1016/j.acalib.2014.04.009

McGill University. (2015a). Enrolment report Fall 2015: Total (FT and PT) enrolments by mother tongue. Retrieved from https://www.mcgill.ca/es/files/es/fall_2015_-_total_fulltime_and_part-time_enrolments_by_mother_tongue.pdf

McGill University. (2015b). Enrolment report Fall 2015: Total (FT and PT) visa enrolments by countries. Retrieved from https://www.mcgill.ca/es/files/es/fall_2015_-_total_fulltime_and_part-time_visa_enrolments_by_countries.pdf

McGill University. (2015c). Enrolment reports. Retrieved from https:/ / www.mcgill.ca/es/registration-statistics

McGill University Library. (2016). Welcome to the McGill library. Retrieved from https://www.mcgill.ca/library/orientation

International Journal on Information, Diversity and Inclusion, Vol. 1, 2016

publish.lib.umd.edu/IJIDI/ 
Morrissey, R., \& Given, L. M. (2006). International students and the academic library: A case study. Canadian Fournal of Information and Library Science, 30(3-4), 221-239.

Nzivo, C. N., \& Chuanfu, C. (2013). International students' perception of library services and information resources in Chinese academic libraries. The fournal of Academic Librarianship, 39(2), 129-137. http://dx.doi.org/10.1016/j.acalib.2012.11.004

Sin, S. C. J. (2015). Demographic differences in international students' information source uses and everyday information seeking challenges. The Fournal of Academic Librarianship, 41(4), 466-474. http://dx.doi.org/10.1016/j.acalib.2015.04.003

Song, Y. S. (2004). International business students: A study on their use of electronic library services. Reference Services Review, 32(4), 367-373.

Zhao, J. C., \& Mawhinney, T. (2015). Comparison of native Chinese-speaking and native English-speaking engineering students' information literacy challenges. The fournal of Academic Librarianship, 41(6), 712-724. http://dx.doi.org/10.1016/j.acalib.2015.09.010

Zhuo, F., Emanuel, J., \& Jiao, S. (2007). International students and language preferences in library database use. Technical Services Quarterly, 24(4), 1-13.

International Journal on Information, Diversity and Inclusion, Vol. 1, 2016

publish.lib.umd.edu/IJIDI/ 